\title{
DE DE GRUYTER OPEN

\section{THE CHALLENGES OF CORPORATE TAXATION IN IRAN: THE CASE OF CONSTRUCTION COMPANIES IN THE PROVINCE OF KURDISTAN}

\author{
GANDOMAN HEIDARI Shaho \\ Islamic Azad University, Sanandaj, Kurdistan, Iran
}

SOLDATOS Gerasimos

American University of Athens, Greece

\begin{abstract}
:
The present paper attempts to investigate the challenges of taxation in Iran based on the tax behavior of construction companies in Kurdistan Province. From a 165 questionnaires, Scheffe and Friedman tests were applied to test the following research hypotheses: Efficiency of tax laws, the role of tax experts in filing correct tax reports, the extent to which willing or unwilling tax noncompliance is detectable, and the effectiveness of penalties considering the case of construction companies. The evidence rejects tax law efficiency as well as the efficiency of the penalty-reward system and confirms the negative impact of tax noncompliance on tax revenue. Also, interestingly enough, neither the input of financial expertise in filling out tax reports nor the role of accounting information when taxable income is reported is shown to be statistically significant. Altogether these results point to a highly problematic tax regime in Iran at least in so far as corporate tax from construction companies in Iranian Kurdistan is concerned.
\end{abstract}

Key words: Iran, tax laws, tax culture, accounting information

\section{Introduction}

The significant role of tax revenue in financing government expenditure is widely acknowledged. Much more so in developing countries where low income levels and absence of tax culture pose serious budget limitations for financing much needed public projects (Kondelaji et al. 2016). In so far as Iran is concerned, country reports by the World Bank for the years 2014 and 2015 and by OECD for 2016 indicate that a major part of Iran's annual budget continues to be driven by the income from the export of gas and oil. Diagram 1 is quite instructive about this trend. The continuing reliance on gas and oil revenue has prevented the development of a sound tax system despite the increasing need for tax revenue and despite the measures taken to improve tax 
institutions (Askari 2013).

The focus in this paper is tax behavior as manifested through Construction companies, which are a major source of income generation in Iran. The collection of tax revenue from these companies has proved to be a major challenge due to its specific nature and accounting standards (Mousavi 2015). In general, corporate tax noncompliance, that is, tax evasion and avoidance, in the pursuit of profit maximization and/or managerial rents, proves to be a major concern of Iranian tax authorities which have to find and implement solutions to the problem for the sake of public interest. The public wonders if companies may be counted among the good citizens as far tax payment is concerned (Nabizadeh 2001).

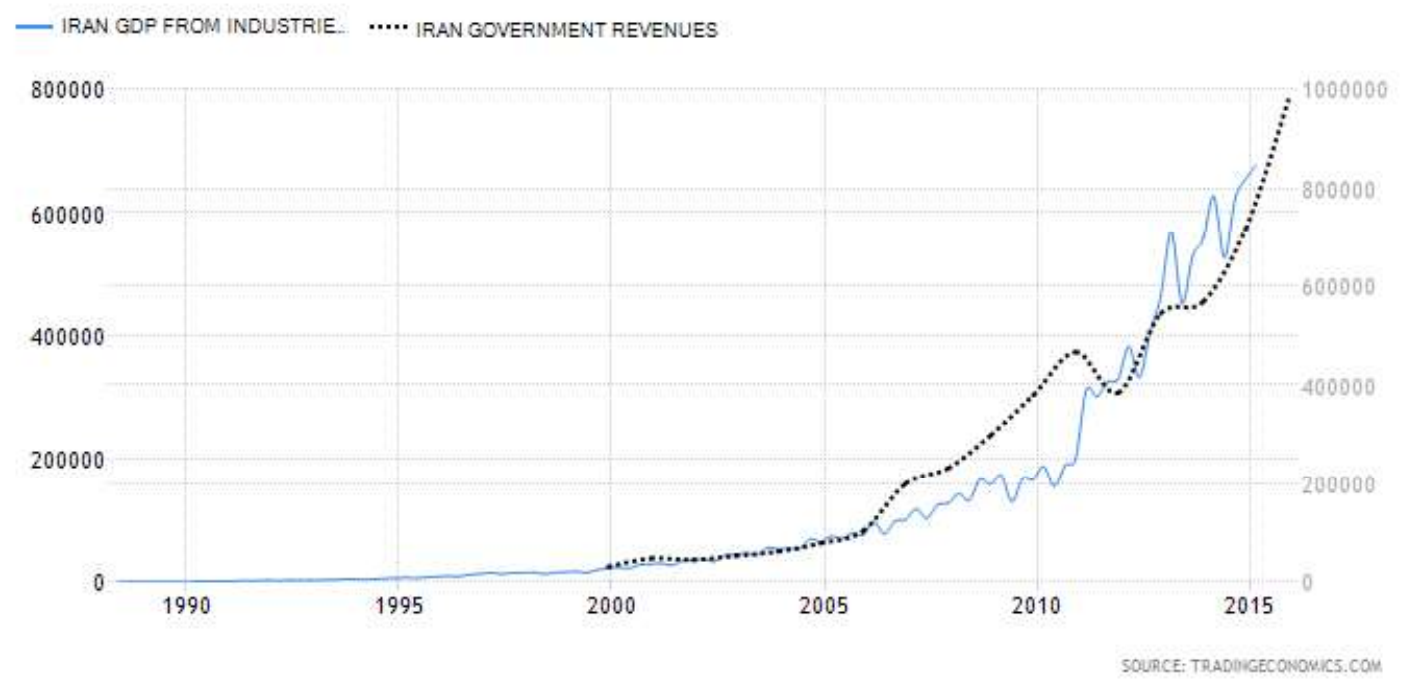

Figure 1. Government revenue and GDP from Mining in Iran

Anyway, the concern herein is on the efficiency of tax laws, the role of tax experts in filing correct tax reports, the extent to which willing or unwilling tax noncompliance is detectable, and on the effectiveness of penalties considering the case of construction companies. Mousavi (2015) showed that quality improvement in auditing by the tax authority in Iran makes the taxation process better. Zarandi and Salimi (2016) emphasize that legal, economic, institutional, structural and political indices have significant influence on tax evasion of foreign tax payers in Iran. Therefore, the phenomenon of tax evasion is a multi-aspect problem that policymakers have to address. Kondelaji et al. (2016) showed that the interplay between conditional cooperation and economic situation in Iran has important effects on tax morality. However, some of the social capital variables such as the importance of politics and religion and demographic factors do not have a significant effect on the morale of tax payers.

Hosseini et al. (2015) showed that the average ratio of underground economy to gross domestic product (GDP) during 1973-2010 in Iran was 16.16\%, which certainly has implications for tax compliance. Azarniyoosh et al. (2016) find a significant difference between the declared taxable income by companies and the taxable income assessed by the tax authorities in Iran. Babajani (2014) elaborates 
upon the significance of the acceleration of all steps in the process of taxation in Iran. Khani et al. (2013) investigate the relationship between the industry expertise of auditor and tax avoidance of companies. They find that there is a significant relationship between the two variables. Zayer (2009) believes that tax law complication has a negative effect on voluntary compliance encouraging tax evasion, and is a barrier to tax fairness and efficiency. Therefore, tax simplification proves to be an essential challenge to the proper design of the Iranian tax system.

In what follows, the next section tries to reassess these findings empirically based on the responses of construction company officers, tax auditors, accounting university faculty, and advanced accounting students to a questionnaire designed so as the following key hypotheses may be tested: (i) The existing laws of taxation from construction companies are efficient enough. (ii) The absence of financial experts in tax report preparation affects tax collection. (iii) Tax non-compliance is not a problem for the tax system. (iv) The penalty-reward system is efficient. And, (v) Accounting information plays a significant role in tax reporting. Section 3 concludes this paper with a discussion of the policy implications of the results.

\section{The Quantitative Analysis}

According to the Organization of Tax Affairs in Kurdistan Province, the number of tax auditors in the region is equal to total 64 . To determine the sample size drawn from this population, Cochran's sample size formula was applied as follows:

$$
n=\frac{64 \times(1 / 96)^{2} \times 0 / 5 \times 0 / 5}{63 \times(0 / 05)^{2}+(1 / 96)^{2} \times 0 / 5 \times 0 / 5}=55
$$

The sample size from tax auditors was thus taken to consist of 55 of them randomly selected. The same size was chosen for the sample of construction company officers too, and another 55 respondents was the sample size from university faculty and students. A total of 165 questionnaires were collected and analyzed. In order to handle the effects of incomplete or missing responses, a $5 \%$ margin of error was taken into account for the sample size. The conceptual model stemming from the literature reviewed earlier and followed here too, is depicted in Diagram 2.

\begin{tabular}{|c|c|}
\hline $\begin{array}{c}\text { Independent } \\
\text { Variable: }\end{array}$ & \\
\hline Tax law adequacy & Dependent \\
Variable: \\
Expertise in tax \\
report preparation & Tax Collection \\
\hline Tax noncompliance & \\
\hline Penalty-reward system & \\
\hline Role of accounting information & \\
\hline
\end{tabular}

Figure 2. The Conceptual Model 
Each of the entries as independent variable in Diagram 2, is analyzed as a factor in data analysis and as a hypothesis to be tested statistically. The Results of Exploratory Factor Analysis (EFA) have as follows. The dependent variable was tested based on the 31 questions included in the questionnaire. Since EFA was conducted within the framework of Principle Components Analysis (PCA), and as it is shown in Table 1, the Kaiser-Meyer-Olkin (KMO) Test for Sampling Adequacy equals 0.802 while according to the results of Bartlett's test of sphericity (significance 0/000), the selected sample is efficient enough. Also, as it is shown in Table 2, the total percentage of variance explained is $63.079 \%$.

Table 1. Results of KMO test and of Bartlett's test of sphericity

\begin{tabular}{|c|c|}
\hline KMO test and Bartlett's test of sphericity \\
\hline KMO index & 0.802 \\
\hline Bartlett's test of sphericity & 3215 \\
\hline DF & 465 \\
\hline significance & 0.000 \\
\hline
\end{tabular}

Table 2. Total Variance by factor-independent variable

\begin{tabular}{|c|c|c|c|c|c|c|}
\hline Factor & \multicolumn{3}{|c|}{ Special values } & \multicolumn{3}{c|}{ Variance explained } \\
\hline $\begin{array}{c}\text { Independent } \\
\text { variable }\end{array}$ & Total & Percentage & $\begin{array}{c}\text { Total } \\
\text { percentage }\end{array}$ & Total & Percentage & $\begin{array}{c}\text { Total } \\
\text { percentage }\end{array}$ \\
\hline 1 & 4.417 & 14.247 & 14.247 & 3.420 & 11.033 & 11.033 \\
\hline 2 & 2.695 & 8.694 & 22.940 & 3.080 & 9.934 & 20.967 \\
\hline 3 & 2.082 & 9.715 & 32.655 & 2.257 & 11.279 & 32.246 \\
\hline 4 & 2.004 & 13.464 & 46.119 & 2.245 & 14.243 & 46.489 \\
\hline 5 & 1.847 & 16.960 & 63.079 & 2.043 & 16.590 & 63.079 \\
\hline
\end{tabular}

Therefore, conducting a factor analysis based on the calculated correlational matrix can be justified. Diagram 3 shows the scree plot of the taxation questionnaire.

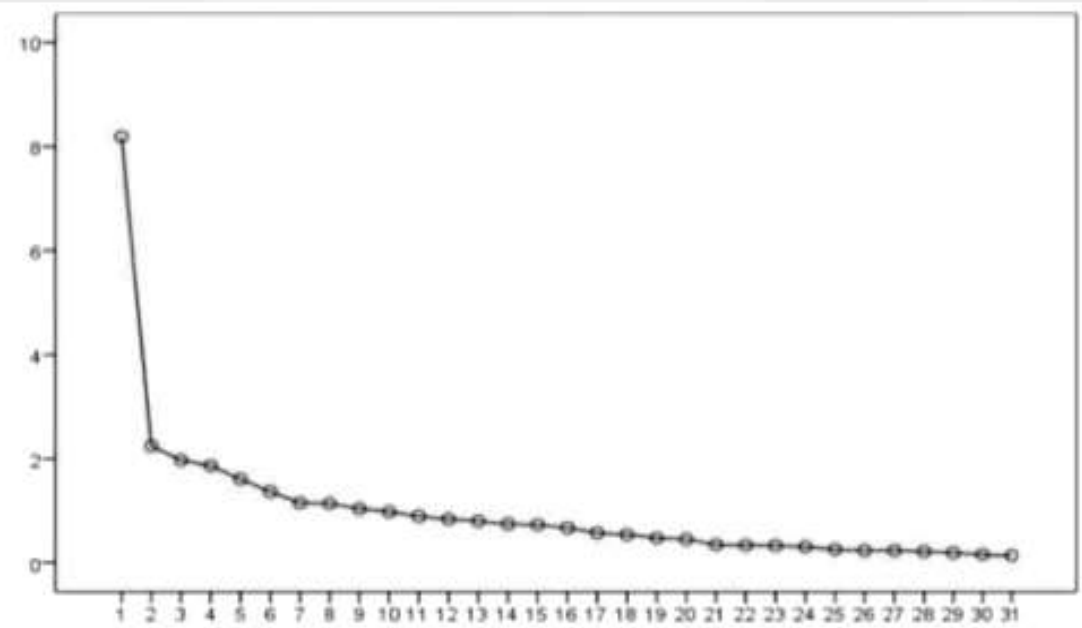

Figure 3. Scree Plot of the taxation questionnaire 
Since both internal consistency for each item and alpha for the questionnaire are greater than 0.7 , the reliability of the questionnaire can be positively interpreted. Furthermore, Cronbach's alpha, which has been calculated as for each of the 3 groups, is greater than 0.7 in each of them.

Table 3. Cronbach' Alpha of the Questionnaire

\begin{tabular}{|c|c|c|}
\hline Total items & Sample size & Cronbach' alpha \\
\hline 31 & 165 & 0.726 \\
\hline
\end{tabular}

Table 4. Cronbach' Alpha of the Questionnaire from the Perception of the Statistical Population

\begin{tabular}{|c|c|}
\hline Statistical Population & Cronbach' alpha \\
\hline Perception of university respondents & 0.792 \\
\hline Perception of tax auditors & 0.798 \\
\hline Perception of company officers & 0.821 \\
\hline
\end{tabular}

Findings based on the analysis of the research variables in Table 5 show that the highest mean from the perception of tax auditors belongs to the factor of accounting information. In fact, they focus more on the factor of transparency in accounting as far as taxation from construction companies is concerned. From the perception of university faculty and students, the involvement of tax experts in the preparation of tax reports accounts for the highest mean (mean=3.872, V. 0.574). Finally, the highest mean from the perception of taxpayers belongs to the use of penalty-reward system.

Prior to testing the research hypothesis, Kolmogorov-Smirnov test (K-S) was applied in order to test the normality of data. Table 6 reports significance levels (sig) on the questionnaires; they are $0.460,0.623$, and 0.521 for the tax auditors, university respondents, and taxpayers, respectively. Therefore, the null hypothesis $\mathrm{H}_{\circ}$ of presence of data abnormality is rejected. The normality of data has been a matter of concern all along the process, indeed.

The result concerning tax law inefficiency is not surprising since it is common knowledge in Iran that there is hardly something that might comprise a thorough and consistent tax system in general. And, because of this perhaps, the result regarding the presence of an inefficient penalty-reward system obtains. Inefficient is a tax system when it is very difficult to navigate and hence, when it is rare to identify instances where tax rules and regulations are explicit enough to allow the tax base to be cross checked and confirmed by the tax authority. So, when taxable income has not been reported adequately by the tax payer, it is not easy to detect it. Worse yet, once tax fraud is detected, the tax system prevents its punishment in a way that would send the message to the public that tax evasion would be an unworthy venture if detected. The opposite should the message be in those rare instances of tax payers, who do not take advantage of the tax-evasion encouraging inadequacies of the tax system and submit 
correct tax reports, which brings us to the results regarding the remaining research hypotheses.

Table 5. Distribution of Means, SD and Variance under the different Hypothesis Test Assumptions

\begin{tabular}{|c|c|c|c|c|}
\hline \multirow{6}{*}{ Tax auditors } & Factor & Mean & SD & Variance \\
\hline & Efficiency of laws & 3.572 & 0.528 & 0.279 \\
\hline & Expertise in tax reporting & 3.673 & 0.510 & 0.260 \\
\hline & Tax noncompliance & 3.723 & 0.404 & 0.163 \\
\hline & Penalty-reward system & 3.688 & 0.470 & 0.221 \\
\hline & $\begin{array}{l}\text { Role of accounting } \\
\text { information }\end{array}$ & 3.771 & 0.525 & 0.276 \\
\hline $\begin{array}{c}\text { Means of the perceptions of } \\
\text { experts }\end{array}$ & & 3.685 & 0.295 & 0.087 \\
\hline \multirow{5}{*}{ University faculty and students } & Efficiency of laws & 3.745 & 0.751 & 0.565 \\
\hline & Expertise in tax reporting & 3.827 & 0.572 & 0.329 \\
\hline & Tax noncompliance & 3.795 & 0.511 & 0.261 \\
\hline & Penalty-reward system & 3.530 & 0.559 & 0.313 \\
\hline & $\begin{array}{l}\text { Role of accounting } \\
\text { information }\end{array}$ & 3.716 & 0.709 & 0.503 \\
\hline $\begin{array}{c}\text { Means of the perceptions of } \\
\text { University elites }\end{array}$ & & 3.723 & 0.388 & 0.151 \\
\hline \multirow{5}{*}{ Company officers } & Efficiency of laws & 3.824 & 0.669 & 0.448 \\
\hline & Expertise in tax reporting & 3.800 & 0.593 & 0.351 \\
\hline & Tax culture & 3.820 & 0.527 & 0.278 \\
\hline & Penalty-reward system & 4.02 & 0.580 & 0.336 \\
\hline & $\begin{array}{l}\text { Role of accounting } \\
\text { information }\end{array}$ & 3.88 & 0.485 & 0.235 \\
\hline $\begin{array}{c}\text { Means of the perceptions of } \\
\text { taxpayers }\end{array}$ & & 3.869 & 0.478 & 0.228 \\
\hline
\end{tabular}

Table 6. Investigation of Data Normality using K-S tes

\begin{tabular}{|c|c|c|c|}
\hline Test & Tax auditors & University respondents & Taxpayers \\
\hline K-S test & 0.553 & 0.674 & 0.867 \\
\hline sig & 0.920 & 0.754 & 0.440 \\
\hline
\end{tabular}


Table 7. Summary of the Results of Hypothesis Testing

\begin{tabular}{|c|c|c|}
\hline Hypothesis: $\mathrm{H}_{\circ}$ & sig & Result \\
\hline Construction company tax laws are inefficient & $0.090>0.05$ & Accept \\
\hline $\begin{array}{l}\text { The absence of financial experts in tax report preparation } \\
\text { influences tax collection }\end{array}$ & $0.046<0.05$ & Reject \\
\hline Tax noncompliance is a problem for the tax system & $0.190>0.05$ & Accept \\
\hline The penalty-reward system is efficient & $0.000<0.05$ & Reject \\
\hline $\begin{array}{l}\text { Accounting information does not play a significant role } \\
\text { in the process of taxation }\end{array}$ & $0.330>0.05$ & Accept \\
\hline
\end{tabular}

When a tax system is poorly designed and implemented, it does not only shape a tax culture of tax evasion but challenges in addition social coherence by raising the issue of unequal treatment by the state and changing income distribution as very well Zayer (2009) notes. Our results corroborate this exactly viewpoint at least in so far as tax culture is concerned. It is tax evasion as an equilibrium phenomenon and this is the reason the quality of tax reports by being prepared expertly and based on accounting detail is considered to be unimportant for tax revenue. As a matter of fact, one explanation of the statistically insignificant role of accounting information is that even accounting systems themselves have been inflicted by the same cultural influences that have shaped the tax culture. The respondents to the questionnaire of this study are aware of "the abnormal evolution of accounting in Iran, the impact of unstable economics, [and of the] inappropriate use of accounting methods and procedures which are common among developing countries..." (Noravesh et al. 2007, p. 254). And, the respondents do in addition know that the quality of the professional conduct of tax auditors has not been such that it would make tax payers endeavor to submit accurate tax reports by seeking help from the experts on the subject (Sedeh and Moradi 2016).

\section{Concluding Remarks}

It is tempting to conclude this study with the single comprehensive policy suggestion to which it leads, namely the systematic development of tax compliance culture given the current tax regime in Iran. The merits of tax compliance should be continually stated to the public through the mass communication means, taught even at highschools, as a matter of improving upon a given social norm. Increasing public awareness regarding budget issues and the social welfare aspect of taxation would certainly increase individual sensitivity to one's task of fulfilling one's own tax obligations. True, but the object of our analysis here was the tax behavior of production enterprises as reflected through the tax behavior of construction companies. They can make rules making tax fraud possible: "Business rules by their nature are excellent at finding known patterns of fraud... [It is necessary to] fully appreciate and understand 
the value of business rules in the detection and prevention of fraud" (Kapranova et al. 2016, pp. 91-92).

This statement summarizes one key practical policy suggestion on the part of this study, too. Tax auditor visits to business premises to view documents, interview staff, etc, aiming at deterring, detecting and addressing non-compliance with the taxation laws, are also a must, encouraging companies to be reassessing their taxation compliance internally. Much more so when construction companies in Iran are prone to manipulating documents (fake invoices, double entry bookkeeping) and subcontractors, rendering actual accounting information quite unreliable, and gaining a favorable tax treatment against any standard of fairness. When a penalty has to be levied, it has to take into account that the inefficiency of penalties in Iran is due to outstanding claims and tax arrears lasting for more than a year, and also due to tax exemptions. Therefore, it is suggested that the government should keep the penalty rate higher than the interest rate, so that tax payers are encouraged to show tax compliance without falling into arrears. The government can also direct assets towards industrially deprived areas through offering tax exemptions and incentives.

Our results herein are more or less shared with those for other developing economies. To mention a few other studies with similar conclusions, Abdul Hamid et al. (2016) found that despite constant encouragement, accountability among Malaysian construction companies has stayed at a low level; they suggest supporting the directors of such companies, and raising tax rewards as practical solutions. Kbiladze (2016) show that inefficiency of tax laws due to unequal tax burden and fixed interest rate taxes for enterprises irrespective of their size and type of activities is a major challenge to the process of tax collection in Georgia. Madugba et al. (2015), having looked at the design and development of a corporate taxation system in Nigeria, found that tax payment can be encouraged through simplification and increased efficiency in payment processing. This is a general conclusion endorsed by this paper in agreement also with Babajani (2014) in that the acceleration of the process of taxation is significantly related to the reporting and recording of the information from the different organizational levels of a company by the different steps of the process before and after the receipt of taxes.

\section{References}

Abdul Hamid, A.R. Abdullah, A., Mohandes, S.R., and Singh, B. (2016). "The Practices of Corporate Social Responsibility among Constructing Companies in Malaysia", International Journal of Applied Sciences, 12(7), 742-755.

Askari, A. (2013). "Dissection of the Tax Reform of the Country", Challenges, Programs and the Tax System operation, 1(2), 85-120.

Azarniyoosh, H. and Majidi, M.J. (2016). "Investigating the Reasons of Difference between Taxable Income and Income Assessed by Tax Authorities (A Case Study: The Tax Offices in Yazd Province)", International Journal of Humanities and Cultural Studies, April Special Issue, 642-649. 
Babajani, J. (2014). "The Role of Information Accounting in the Acceleration of Tax Receiving process from the Perception of Financial Experts", Experimental Research in Accounting, 3(10), 1-20.

Hosseini, A., Nasrollahi, Z., and Abtahi, S.Y. (2015). "Review of Underground Economy Developments in Iran", Journal of Novel Applied Sciences, 4(3), 351-359.

Kapranova, L., Stankevičius, A., Simanaviciene, Z., and Lukšaite, A. (2016), "Tax Morale and Tax Evasion: Theoretical Insights", Public Security and Public Order, 16, 80-95.

Kbiladze, T. (2016). Tax Burden for the Companies in Georgia, Management Theory and Studies for Rural Business and Infrastructure Development, 38(1), 28-35.

Khani, A., Imani, K., and Molaei, M. (2013). "Investigating the Relationship between the Industry Expertise of Auditor and Tax Avoidance of Companies Listed in Tehran Stock Exchange", Journal of Audit Science, 13(51), 43-68.

Kondelaji, H., Sameti, A., and Moayedfar (2016). "Analyzing Determinants of Tax Morale based on Social Psychology Theory: Case study of Iran", Iranian Economic Review, 20(4), 581-598.

Madugba, J.U., Ekwe, M.C. and Kalu, J.M. (2015). "Corporate Tax and Revenue Generation: Evidence from Nigeria", Journal of Emerging Trends in Economics and Management Sciences, 6(5), 333-339.

Mousavi, S.E. (2015). "A Survey in the Status of Instrumental, Diagnostic and Certain Taxes", Teknologi Tanaman, 12, Supp (2), 351-354.

Nabizadeh, H.R. (2001). Investigating Information Content of the Elements of Financial Statements based on Tax Laws from the Perception of Stakeholders, MSc Thesis, Faculty of Management and Accounting, University of Tehran.

Noravesh, I., Dianati Dilami, Z., and Bazaz, M.S. (2007) "The Impact of Culture on Accounting: does Gray's Model Apply to Iran?", Review of Accounting and Finance, 6(3), 254 -272.

OECD (2016). Development Co-operation Report 2016: The Sustainable Development Goals as Business Opportunities, OECD Publishing, Paris.http://dx.doi.org/10.1787/dcr-2016en

Sedeh, S.A., and Moradi, M.A. (2016), "Studying the Role of Professional Conduct of Tax Auditors in Reducing Tax Evasion from the Viewpoint of Isfahan Tax Affairs Experts", International Business Management, 10(19), 4460-4469.

Zarandi, F. and Salimi, F. (2016). "Studying the Impediments and Problems of Taxation from Agency Offices and Branches of Foreign Companies in Iran", Journal of Administrative Management, Education and Training, 12(4), 459-470.

Zayer, A. (2009). "The Status of Simplification in Tax Reform Plans: Global Experience and the Chanllenges for the Iranian Tax System", Journal of Tax Research, 17(6), 157-184. 